\title{
HOMENAGEM DE VIDA
}

\section{O JOÃO QUE CONHECI}

\section{Guilherme Silva de Almeida ${ }^{1}$}

Não considero João um homem da minha geração. Para mim, ele compôs a primeira geração de homens trans brasileiros, que tem mais de 60 anos e da qual se sabe muito pouco. É possível saber que os que daquela geração realizaram modificações corporais, o fizeram em condições de clandestinidade, dentro ou fora do Brasil, assim como enfrentaram muitas limitações nas tecnologias biomédicas disponíveis. Eles foram anteriores ou concomitantes à emergência do feminismo da segunda onda, do movimento LGBT e do movimento negro no país. Além disso, eles tiveram dificuldades para o reconhecimento jurídico da sua condição e, por terem vivido tais experiências em grande medida no contexto ditatorial, bem como pela muito menor visibilidade pública das discussões de gênero com a qual lidaram, tenderam a ocultar sua condição de transexual após a transição.

Faço parte da segunda geração de homens trans, homens que hoje estão entre 45 e 55 anos, sobre os quais se sabe um pouco mais, porque tiveram maior aparição pública. Destaco como principais questões vividas pela segunda geração, a inexistência de uma identidade pública como homem transexual consolidada na esfera pública brasileira, terem se tornado, ainda que temporariamente, representantes políticos dos homens trans, bem como o fato de terem realizado suas modificações corporais já no âmbito do processo transexualizador ainda incipiente. Eles enfrentaram dificuldades para obter a retificação judicial de nome e sexo e reconhecimento público como homens transexuais, principalmente nos seus espaços de trabalho, comunitárias e familiares, sobretudo pela pouca visibilidade das questões trans durante sua juventude e parte da vida adulta. Por já terem vivido suas transições no contexto democrático e na presença do movimento LGBT,

\footnotetext{
${ }^{1}$ Assistente Social. Professor da Escola de Serviço Social da Universidade Federal do Rio de Janeiro (ESS/UFRJ). Doutor em Saúde Coletiva pelo Instituto de Medicina Social da Universidade do Estado do Rio de Janeiro (IMS/UERJ). E-mail: gsdealmeida@gmail.com
}

Vol. 01, N. 04, Out. - Dez., 2018 - www.revistas.unilab.edu.br/index.php/rebeh 
entretanto, ousaram com maior frequência, expor publicamente sua condição transexual. Tiveram maior acesso à informação sobre transexualidade em geral, mas só aos poucos sobre transexualidade masculina. Nela destaco a presença de nomes como: Alexandre Peixe (SP), Rai Carlos (PA), Silvyio Luccio (CE), Régis Vascon (SP), Jordhan Lessa (RJ), Thiago Nery (MG) e Gabriel Graça (DF). São jovens senhores, alguns já vovôs. Abaixo dessa, há uma terceira geração que tem entre 30 e 45 anos. Trata-se de uma geração intermediária que viveu suas transições já conhecendo alguns homens transexuais e estabelecendo interlocuções com eles. Essa geração já se estabeleceu a partir do acesso às redes sociais e contribuiu para e/ou participou de grupos exclusivos de trans. Destaco alguns nomes dela: Leonardo Tenório (PE), Leonardo Peçanha (RJ), Raul Capistrano (MG), Marcelo Caetano (DF), Benjamin Braga (MS), entre muitos outros. É uma geração que já tinha algum acesso ao processo transexualizador, produziu lideranças trans e trouxe algumas questões novas à pauta dos homens trans: acesso à universidade, homo/bissexualidade trans, pertencimento racial, não-binarismo, parentalidade, destransicionamento, entre outras. Abaixo dela, já há uma quarta geração de homens trans e não-binários que tem menos de 30 anos e é a mais numerosa de todas. Recupero essa classificação um tanto quanto arbitrária, somente para que seja dito que João incidiu sobre todas elas e as influenciou de diferentes formas.

Era 2007 e eu tinha comunicado aos meus amigos que minha transição de gênero tinha começado. Naquele ano tinha ingressado como usuário do HUPE/UERJ e conhecido o primeiro homem trans de carne e osso que já tinha realizado modificações corporais cirúrgicas, naquele mesmo hospital. Fora aquele que eu tinha conhecido na sala de espera, mais ninguém. Recebi então, como presente das minhas amigas Ilma Doher e Kátia Leão, um livro que elas encontraram num sebo chamado Erro de Pessoa. Nele, um sujeito de algum lugar do Brasil narrava com o codinome João W. Nery, em 1983, sua transição de gênero vivida nos anos de 1970, em plena Ditadura Militar.

Depois de ler fiquei curioso: estaria esse homem vivo ou morto? Satisfeito ou insatisfeito com as mudanças? Moraria em que lugar do país? Teria concretizado seus sonhos? Só saberia algumas dessas respostas cerca de três anos depois, quando João reapareceu lançando seu segundo e, também belo livro, Viagem Solitária. Fui com os professores Vanessa Leite e Marcos Nascimento e a também professora australiana e 
mulher trans, Raewyn Connell (que então visitava o Brasil a convite do IMS/UERJ), ao lançamento na Livraria Travessa.

Lá descobri que João era um homem simples, acessível, vivaz e inteligente. Foi bom encontrá-lo antes que as mídias e as redes sociais o transformassem num mito e quase o devorassem vivo. João fumava menos e era bem menos estressado naquele momento. Eu conheci outras biografias trans antes das do João, mas conhecer as dele me mostrou a viabilidade das existências trans tupiniquins. Além de adquirir mais confiança para continuar meu próprio caminho de afirmação identitária, vi João ocupar o papel histórico de ser pai, não apenas pai do seu legítimo filho, mas pai de muitos homens trans que ele partejava com diligência através das redes sociais. Ele fazia isso com maestria e prazer de educador. Não fazia acepção de pessoas e não se deixou tragar pelas disputas comuns e tão frequentes nos movimentos sociais.

Vi João se fazer porta-voz em espaços midiáticos que eu, pessoalmente, não suportaria entrar, mas ele, pondo provavelmente a repulsa de lado, foi lá falar. Vi João jamais fechar as portas para qualquer convite e eles chegaram em profusão: para inumeráveis eventos acadêmicos, de produção de conhecimentos, para virar tema de dissertação, para personagem de outros livros, para consultor de TV e sabe-se lá mais o quê. Ele parecia incansável e parecia também querer compensar o tempo em que por força do contexto ditatorial e de ausência total de direitos das pessoas trans no país, em que se fez jovem e adulto, permaneceu calado.

Vi João aceitar o convite para compor o GT da então Reitoria da UERJ, do qual também fazia parte, para pensar junto uma proposta muito mais completa para o atendimento a pessoas trans no RJ e trabalhamos exaustivamente nisso, por meses. Vi João se amargurar também, como eu, com os fracassos de muitos de nossos empenhos, esbarrando no mar de desalento que tomou conta da política brasileira e fluminense nos últimos anos e que afetou todos os serviços públicos pelos quais lutamos para que existissem: centros de cidadania LGBT, hospitais especializados no processo transexualizador, universidades.

Jamais nos frequentamos como amigos em espaços particulares. Não deu. Minha própria vida corrida e também a dele, permitiu apenas encontros e conversas espremidas nos inúmeros eventos compartilhados, nas roubadas esquinas de bar, no esbarrão do banheiro, nas portarias dos prédios de universidades e centros de convenções em que

Vol. 01, N. 04, Out. - Dez., 2018 - www.revistas.unilab.edu.br/index.php/rebeh 
fomos trabalhar. Sempre encontrados: mútua reverência e respeito. Parceiros de luta que podiam inclusive discordar em alguns poucos aspectos, como na polêmica sobre o uso da expressão homem trans ou transhomem... que diferença faz? Nenhuma. Falávamos da mesma coisa, da elevação honrosa da identidade trans masculina à esfera pública brasileira, de cidadania, do direito à vida plena. Sem rodeios. Sem desculpas. Sem invisibilização. Com reflexão. Sem cooptação por quaisquer forças políticas oportunistas. Sem descanso.

Não haverá outro João. João se fez homem na Ditadura e devo dizer que ele nunca

deve ter imaginado nos seus piores pesadelos que morreria às vésperas da ameaça de outra coalisão de militares. João não lutou por privilégios ou particularismos. Homem admirável que teve que viver como exilado dentro do próprio país por décadas para ter sua identidade reconhecida, enquanto milhares de pilantras se criam nesse mesmo país como pessoas respeitáveis, por força do poder econômico e do uso de armas.

Ele foi o único da geração dele que ousou dar a cara pública, embora sempre tenha afirmado que havia outros tantos homens trans que transicionaram na mesma época que ele. Sua viagem foi mais solitária, não pela ausência total de apoios, mas talvez pela ausência de outros que tivessem vivido pelo menos algumas de suas dores e conquistas. Talvez por isso também tenha se entregado tanto ao cuidado e acompanhamento de jovens trans, muitos dos quais poderiam ser seus netos: por não desejar que a solidão desse cria, mas que houvessem alianças entre as pessoas trans.

João não criou nem conduziu pessoalmente um grupo político formal que integrasse o movimento trans, tampouco presidiu ou integrou organizações existentes. Ao contrário, circulou entre as instituições formais, contribuiu para articulações entre elas e delas com o Estado e, através da internet, aproximou e recenseou os que atualmente são milhares de homens trans no país. Ele entendeu que seria mais útil como ícone que oferecia um bom exemplo, muita escuta e conhecimento aos recém-chegados. Ele entendeu que seria mais útil também como intelectual orgânico do tema. Aproximou-se também da academia, escreveu artigos e estava prestes a ser homenageado com um justíssimo Honoris Causa quando faleceu, que visava reparar o estrago histórico feito na carreira do brilhante psicólogo e professor que sacrificou carreira e títulos na década de 1970, para ser ele mesmo. Quem um dia, como eu, temeu que tivesse que fazer essa escolha (no começo dos anos 2000), consegue imaginar bem como deve ter sido penoso

Vol. 01, N. 04, Out. - Dez., 2018 -www.revistas.unilab.edu.br/index.php/rebeh 
para ele e sua família, abrir mão de anos de investimento e estudo para tornar-se legalmente analfabeto, como ocorreu nos primeiros anos da transição dele e submeter-se a partir daí a todo tipo de trabalho precário.

João era de uma capacidade de doação política rara. Não buscou ganhos pessoais com sua militância. Tinha por perspectiva a utopia da plena conquista de direitos e melhores condições de vida, principalmente, mas não somente, para as pessoas trans. Era feminista e não pactuava com atitudes racistas nem homofóbicas.

Inspiração para muitos de nós, ele resistiu tanto quanto pôde e talvez tenha descansado da doença apenas quando teve certeza de que sua tocha seguia acesa empunhada por sempre novas mãos e não poderá ser apagada. Não haverá outro João, mas sempre haverá sua memória, seu exemplo, sua inspiração. Não nos esqueçamos dele, do seu testemunho de ousadia, obstinação, fé e sororidade e de todas as outras pessoas que se empenham para a construção de uma verdadeira democracia no nosso país. A falta de memória condena países e indivíduos a velhos erros. Salve João! Luz no seu caminho e que sua luz permaneça reverberando nas trilhas de cada jovem Trans que emergir nesse perturbado país. 